\title{
TERAPI TAWA UNTUK MENGURANGI EMOSI MARAH PADA CAREGIVER LANSIA
}

\section{LAUGHTER THERAPY TO REDUCE ANGER EMOTION IN AGEING CAREGIVER}

\author{
Nandhini H. Anggarasari \\ H. Fuad Nashori \\ RA Retno Kumolohadi \\ Fakultas Psikologi dan Ilmu Sosial Budaya Universitas Islam Indonesia Yogyakarta \\ Email: nandhinihagrs@yahoo.com
}

\begin{abstract}
This study aims to determine the effectiveness of laughter therapy to reduce emotional upset at ageing caregivers. Subject retrieval technique used was purposive sampling method. Subjects numbered 20 people, divided into experimental group and control group, with the following criteria: women or men who care for the elderly, fill out the medical records. The STAXI scale and open scale used was developed by Spielberger, which reveals the emotion of anger. Experimental method used is a quasi-experimental, nonrandomized design using pretest-posttest control group design. Based on the test results of pre-test and post-test in the experimental and control groups, using analysis of T-Test, gain scores obtained score $F=$ 0,296 and a score of 0,478 (2-tailed)/ 0,593 (1-tailed). Score $p>0.01$, indicating no difference between the experimental group and the control group after therapy. However, based on open questionnaire, subjects felt calmer and fitter after laughter therapy is done, feel that this therapy is very beneficial and should be disseminated to the public
\end{abstract}

Key words : ageing caregivers, anger emotion, laughter therapy.

\begin{abstract}
ABSTRAK
Penelitian ini bertujuan untuk mengetahui efektivitas terapi tawa untuk mengurangi emosi marah pada caregiver lansia. Teknik pengambilan subjek yang digunakan adalah metode purposive sampling. Subjek penelitian berjumlah 20 orang, yang terbagi menjadi kelompok eksperimen dan kelompok kontrol, dengan kriteria wanita atau laki-laki yang mengasuh lansia dan mengisi rekam medis. Adapun skala yang digunakan adalah STAXI yang disusun oleh Spielberger, yang mengungkap emosi marah dan skala terbuka. Metode eksperimen yang digunakan adalah kuasi eksperimental, dengan menggunakan nonrandomized pretestposttest control group design. Berdasarkan hasil uji prates dan pascates pada kelompok eksperimen dan kelompok kontrol, dengan menggunakan analisis t-Test, gain score diperoleh skor $F=0,296$ dan skor $p$ sebesar 0,478 (2-tailed)/ 0,593 (1-tailed). Skor $p>0,01$, menunjukkan tidak adanya perbedaan antara kelompok eksperimen dan kelompok kontrol setelah terapi. Namun, berdasarkan angket terbuka, subjek merasa lebih tenang dan bugar setelah terapi tawa dilakukan, merasa bahwa terapi ini sangat bermanfaat dan sebaiknya disosialisasikan pada masyarakat luas.
\end{abstract}

Kata kunci : Terapi tawa, emosi marah, caregiver lansia. 
Lanjut usia atau lansia, suatu istilah yang diberikan kepada individu yang telah mencapai usia 60 tahun ke atas, merupakan periode penutup dalam rentang hidup seseorang. Ada banyak perubahan yang terjadi pada masa lansia dibanding periode-periode hidup sebelumnya, di antaranya perubahan secara fisik (penampilan, bagian dalam tubuh, fungsi fisiologis, panca indera), perubahan motorik, perubahan seksual, serta kemampuan mental, dan minat (Hurlock, 1994). Pada lansia ada perubahan peran, di mana efisiensi, kekuatan, kecepatan, dan daya tarik fisik mulai berkurang.

Perubahan-perubahan itu sering mengakibatkan lansia dianggap merasa tidak ada gunanya lagi, karena mereka tidak dapat bersaing dengan orang-orang yang lebih muda dalam berbagai bidang. Perasaan tidak berguna dan tidak diperlukan lagi bagi lansia menumbuhkan rasa rendah diri dan kemarahan, yaitu suatu perasaan yang tidak menunjang proses penyesuaian sosial seseorang (Hurlock, 1994).

Dikarenakan berkurangnya fungsifungsi dan perannya, lansia umumnya membutuhkan pengasuh dalam menjalani kehidupannya sehari-hari. Pengasuh lansia atau biasa disebut pramurukti (caregiver) adalah individu yang mengasuh dan merawat lansia di rumah. Proses yang terus menerus yang dialami pramurukti dalam menghadapi lansia menimbulkan kejenuhan dan tekanan serta memberikan dampak yang negatif terhadap emosi dan perilaku sehari-hari. Beberapa pengasuh, pekerja sosial, dan karyawan di panti werdha mengakui bahwa mereka membutuhkan agenda atau aktivitas yang berfungsi untuk mengurangi dan menetralkan segenap tekanan yang ada. Berdasarkan hasil wawancara dengan beberapa pengasuh di panti werdha " $X$ " diketahui ada agenda dari panti untuk mengadakan penyegaran kembali bagi pramurukti, perawat, tenaga sosial, dan seluruh karyawan di panti, seperti senam bersama dan sesekali rekreasi. Namun, semenjak ada pengganti kepala panti, semua itu tidak pernah dilakukan lagi.

Tekanan atau stress yang menimbulkan kecemasan dapat menimbulkan rasa marah. Rasa marah adalah perilaku emosional yang bergerak karena kondisi yang tidak menyenangkan (Kazhim, 2009). Dalam kondisi seperti ini biasanya orang yang marah akan kehilangan akal dan keseimbangan. Dalam menyikapi rasa marah ada tiga hal yang biasa dilakukan, yaitu merasa dirinya kuat, merasa dirinya tidak kuat, dan ada pula yang dapat mengungkapkan secara verbal. Pengasuh yang merasa dirinya kuat dan benar lebih cenderung untuk menantang lansia, bersikap ketus, kadang membentak, dan kadang kasar terhadap lansia. Pengasuh yang merasa tidak kuat lebih cenderung melarikan diri dan mengingkari amarah, misalnya pura-pura sibuk ketika ada lansia yang membutuhkannya atau sesegera mungkin beralih kegiatan ketika bertemu atau berbincangbincang dengan lansia. Pengasuh yang mengungkapkan secara verbal dapat 
mengekspresikan rasa marahnya atau tidak sukanya dengan tenang dan tidak kentara, sehingga dapat diterima oleh lansia dan orang lain, dan hubungan yang terjalin tetap terjaga (Mulyono \& Purwanto, 2006).

James dan Lange (Atkinson \& Atkinson, 2005) meyakini bahwa faktor yang penting dalam emosi yang dirasakan individu adalah umpan balik dari perubahan badani yang terjadi sebagai respons terhadap situasi yang menakutkan atau membingungkan. Gambaran umpan balik diterangkan melalui gambar berikut:

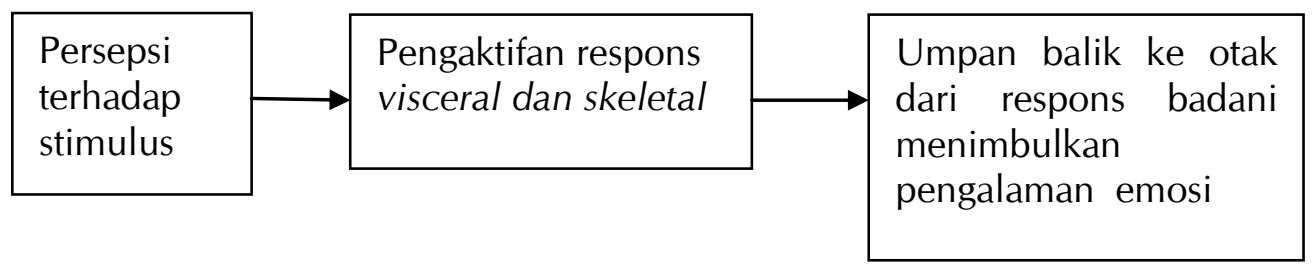

Gambar 1. Proses terjadinya emosi.

Spielberger (1988) menyatakan bahwa marah adalah emosi negatif yang dialami oleh seseorang, yang dapat menimbulkan suatu perasaan terganggu dan tidak nyaman. Kemarahan dapat disertai oleh tanda-tanda fisiologis yang berupa menegangnya otot-otot dan terjadinya percepatan dalam peredaran darah. Spielberger menyatakan bahwa kemarahan terbagi menjadi dua komponen, yaitu pengalaman marah dan ekspresi kemarahan. Pengalaman kemarahan terdiri atas keadaan marah dan sifat marah (state and trait state). Keadaan marah (state anger) diartikan sebagai suatu keadaan emosi yang ditandai dengan perasaan-perasaan subjektif yang bervariasi dari rasa kecewa yang ringan atau jengkel sampai dengan kemarahan yang intens atau meledakledak. Keadaan marah pada umumnya disertai dengan ketegangan otot dan bangkitnya sistem syaraf otonom.
Menurut Schieman (1999), kemarahan terjadi disebabkan oleh beberapa faktor, yaitu perasaan terancam bahaya, tidak ada kesetaraan, ada keadaan yang memalukan, lingkungan dan peranan sosial, dan sikap orangtua terhadap anak. Perasaan terancam dapat dipicu bukan saja oleh ancaman fisik langsung, melainkan juga oleh harga diri atau martabat, diperlakukan tidak adil atau dikasari, dicaci maki atau diremehkan, dan frustrasi.

Sebagai orang yang berada dalam fase dewasa, pengasuh perlu sekali dapat mengendalikan rasa marah, dan akhirnya dapat memberikan dukungan sosial pada lansia. Pada fase ini, proses menerima dan penyesuaian diri, serta menjalin hubungan yang hangat dengan orang lain, termasuk lansia, merupakan salah satu tanda kepribadian yang matang. Bila seseorang pada fase dewasa tidak dapat melalui proses ini, maka selanjutnya dia 
tidak menjalani kehidupan dengan penuh rasa cinta dan puas (Schultz, 1991).

Individu yang memiliki kepribadian yang matang dan sehat mampu menerima emosi-emosinya. Individu tersebut juga mampu mengontrol emosi-emosi mereka, sehingga emosi-emosi ini tidak mengganggu aktivitas antarpribadi. Kontrol emosi bukan merupakan sebuah represi. Emosi-emosi diarahkan kembali ke dalam saluran-saluran yang lebih konstruktif. Kualitas emosi tersebut oleh Allport (Schultz, 1991) disebut "sabar terhadap kekecewaan", yang menunjukkan bagaimana seseorang bereaksi terhadap tekanan dan terhadap hambatan dari keinginankeinginan. Individu yang sehat sabar menghadapi kemunduran-kemunduran, tidak menyerah pada kekecewaan, tetapi mampu memikirkan cara-cara yang berbeda untuk mencapai tujuan dan niat yang baik. Sebaliknya, orang yang neurotis menyerah pada emosi yang dominan pada saat itu, memperlihatkan kemarahan atau kebencian, betapapun perasaan-perasaan itu mungkin tidak tepat.

Ada beberapa terapi yang dapat dilakukan untuk menangani kemarahan, yaitu terapi agama dan terapi psikologi seperti terapi kognitif, terapi cognitive behavioral therapy, dan brief group therapy. Selain itu juga ada terapi relaksasi dan terapi tawa.

Menurut Cogan (1987), relaksasi memiliki efek yang sama dengan tertawa. Ketika individu tertawa terjadi pelepasan endorfin dalam otak. Endorfin adalah endogenous opioid peptida yang berfungsi sebagai neurotransmitter. Endorfin dihasilkan oleh kelenjar pituitary dan hipotalamus dalam vertebrata selama latihan, kegembiraan, merasa sakit, mengkonsumsi makanan pedas, merasakan cinta dan orgasme. Endorfin menyerupai opiat dalam kemampuan mereka untuk menghasilkan analgesia dan rasa sejahtera. Endorfin dapat memberikan rasa santai, gembira pada seseorang. Fungsi endorfin seperti zat morfin yang berasal dari dalam tubuh (Tse, 2010).

Menurut Middleton (2007), tawa merupakan humor yang menjadi warisan budaya dan dapat berperan dalam proses psikoterapi dalam membangun terapeutik aliansi. Richman (2006) menambahkan bahwa humor dapat membantu dalam aktivitas sosial terutama pada lansia, memberikan penilaian dan juga psikoterapi. Hageseth (Billig, 2005) mengungkapkan bahwa tertawa merupakan humor yang positif, yang dapat menyebabkan seseorang menjadi optimis. Sedangkan humor yang negatif lebih mengekspresikan ejekan, sindiran halus bahkan sindiran yang tajam, ataupun humor terkait dengan sisi kekurangan suatu suku bangsa. Tidak semua orang dapat menerima humor yang negatif.

Berdasarkan uraian di atas, yang mempertimbangkan bahwa marah sering dialami oleh pengasuh ketika menghadapi lansia, peneliti bermaksud menunjukkan bahwa marah dapat diatasi dengan salah satu terapi, yaitu terapi tawa. Terapi tawa memiliki efek yang sama seperti relaksasi 
yang dapat meredamkan rasa marah dan memberi ketenangan dan welas asih. Oleh karena itu, peneliti ingin meneliti efektivitas terapi tawa terhadap penurunan rasa marah yang dialami oleh pengasuh.

Tertawa adalah gejala reaksi fisik seseorang yang menerima rangsangan batiniah (lucu) atau badaniah (gelitik) atau faal (penyakit), bisa juga dampak dari rangsangan kimiawi. Tertawa dapat membuat manusia sehat, baik bagi fisik, mental, maupun suasana komunikasi. Tetapi dapat pula tidak sehat bahkan berbahaya dan mengganggu hubungan antar manusia apabila tertawa tidak pada tempatnya, mengganggu kesehatan seperti sesak nafas, kejang perut, atau karena wabah penyakit (Kataria, 2004).

Simulasi tawa adalah suatu bentuk tawa untuk mencapai kegembiraan di dalam hati yang dikeluarkan melalui mulut dalam bentuk suara tawa atau senyuman yang menghias wajahnya, perasaan hati yang lepas, dan bergembira, dada yang lapang, peredaran yang lancar, yang bisa mencegah penyakit dan memelihara kesehatan.

Dari penjelasan di atas, peneliti mengajukan hipotesis penelitian bahwa ada penurunan emosi marah pramurukti pada kelompok eksperimen dibandingkan dengan kelompok kontrol setelah mendapat terapi tawa.

\section{METODE PENELITIAN}

\section{Rancangan Penelitian}

Penelitian ini merupakan penelitian kuasi eksperimen (quasy experiment). Desain yang digunakan adalah nonrandomized pretest-posttest control group design. Penjelasan atas desain dapat dilihat pada tabel berikut:

Tabel 1. Desain Eksperimen

\begin{tabular}{ccccc}
\hline Kelompok & Prates & Perlakuan & Pascates & Tindak Lanjut \\
\hline KE & $(\mathrm{X}) 1$ & $(\mathrm{Y})$ & $(\mathrm{X}) 2$ & $(\mathrm{X}) 3$ \\
$\mathrm{KK}$ & $(\mathrm{X}) 1$ & - & $(\mathrm{X}) 2$ & $(\mathrm{X}) 3$ \\
\hline
\end{tabular}

\section{Keterangan :}

KE : Kelompok Eksperimen

KK : Kelompok Kontrol

(X) : Angket Emosi Marah

(X)1 : Angket Emosi Marah saat pre test

(X)2 : Angket Emosi Marah saat post test

(X)3 : Angket Emosi Marah saat Follow Up

(Y) : Terapi Tawa 


\section{Subjek Penelitian}

Subjek penelitian berjumlah 20 orang, yang terbagi menjadi kelompok eksperimen dan kelompok kontrol, dengan kriteria wanita atau laki-laki yang mengasuh lansia, mengisi rekam medis yang menunjukkan bahwa subjek tidak memiliki penyakit hernia, wasir parah, penyakit jantung dengan sesak nafas, telah melakukan operasi pada bagian perut selama 3 bulan terakhir, peranakan turun, kehamilan, pilek dan flu, batuk lebih dari 10 hari, dan komplikasi mata (glukoma). Pengambilan data dilakukan sebanyak tiga kali, yaitu prates, pascates, dan tindak lanjut.

\section{Metode Pengumpulan Data}

Penelitian ini menggunakan alat ukur dan alat bantu penelitian, yaitu skala STAXI dan angket terbuka. Alat ukur yang digunakan adalah STAXI, yang merupakan adaptasi alat untuk mengukur pengalaman dan ekspresi marah yang disusun oleh Spielberger (1988). STAXI terdiri atas 31 aitem, dari sejumlah aitem tersebut nama dan komponen-komponen marah. Koefisien korelasi aitem-total skala bergerak antara 0,312 sampai dengan 0,630 . Sementara koefisien alphanya 0,875 . Selain itu, kepada subjek juga diminta untuk mengisi angket terbuka yang mengungkap perasaan atau emosi subjek penelitian.

\section{Prosedur Penelitian}

Prosedur terapi adalah tahap-tahap yang dikenai pada subjek sebelum, ketika, dan setelah penelitian. Sebelum pelaksanaan intervensi, terlebih dulu dilakukan prates dengan menggunakan metode angket yang sudah dilakukan uji coba. Selain prates juga dilakukan penandatanganan informed consent oleh kader-kader posyandu lansia dan penjelasan mengenai apa saja yang perlu dipersiapkan untuk mengikuti pelatihan. Setelah pelaksanaan intervensi peserta akan langsung diberikan pascates serta lembar evaluasi reaksi dan pengetahuan.

Terapi ini diberikan oleh seorang terapis yang memiliki pengetahuan tentang terapi tawa dan pernah mempraktekkannya di posyandu lansia dan ruang kelas. Terapi ini ditujukan untuk pramurukti dan dirancang dengan tujuan untuk membantu pramurukti menurunkan emosi marahnya ketika berhadapan dengan lansia.

Modul terapi ini disusun berdasarkan dari tahap-tahap terapi tawa yang disusun oleh Kataria (2004), dan didukung oleh beberapa penelitian sebelumnya yang terkait dengan proses terapi tawa. Modul terapi tawa terdiri atas pendahuluan, waktu pelaksanaan, peserta, tempat pelaksanaan, dan langkah-langkah pelaksanaan terapi. Tahapan-tahapan terapi tawa ini telah dipraktekkan oleh Kataria (2004), dan telah diteliti oleh Shahidi (2010) dan Nugraheni (2006). Langkah-langkah pelaksanaan terapi, adalah sebagai berikut:

Pertama: Tahap awal atau pemanasan (stretching). Tahap pemanasan terdiri atas (a) Terapis mengajak peserta untuk 
membentuk lingkaran atau setengah lingkaran. Para peserta diajak untuk mengikuti aba-aba yang terapis lakukan. (b) Terapis mengajak untuk melakukan langkah 1, yaitu bertepuk tangan seirama 1-2, 1-2-3, sambil mendaras "Ho-HoHo...Ha-Ha-Ha..." (c) Terapis mengajak untuk melakukan langkah 2, yaitu pernafasan dalam dengan tarikan nafas melalui hidung dan dihembuskan pelanpelan. (Bersama kata-kata penyembuhan--memaafkan, melupakan, hidup dan tetap hidup (5 kali). (d) Terapis mengajak untuk melakukan langkah 3, yaitu latihan bahu, leher, dan peregangan (masing-masing 5 kali).

Kedua: Tahap inti. Tahapan inti (Shahidi, 2010) terdiri atas (a) tawa bersemangat, (b) tawa sapaan, (c) tawa penghargaan, (d) tawa satu meter, (e) Tawa milk shake (sebuah variasi), (f) tawa hening tanpa suara, (g) tawa bersenandung dengan mulut tertutup, (h) tawa mengayun, (i) tawa singa, (j) tawa ponsel, (k) tawa bantahan, (l) tawa memaafkan/ meminta maaf, (m) tawa bertahap, (n) tawa dari hati ke hati (tawa keakraban).

Ketiga: Tahap akhir. Tahap akhir terdiri atas langkah berikut ini: (a) Terapis mengajak untuk melakukan teknik penutupan, yaitu dengan cara cara meneriakkan kata-kata positif, seperti "Aku orang paling bahagia di dunia ini", "Aku orang paling sehat di dunia ini", dan "Aku orang paling keren di dunia ini." (b) Terapis mengajak untuk memejamkan mata dan berdoa bersama selama satu menit untuk perdamaian dunia.

\section{Metode Analisis Data}

Data yang diperoleh adalah data kuantitatif, metode analisis data digunakan untuk menguji hipotesis penelitian ini, yaitu menggunakan teknik analisis uji t-Test. Untuk menjaga keakuratan dan kemudahan pengolahan data digunakan teknik perhitungan data melalui program Software Statistical Product and Service Solution (SPSS) 13 for Windows. Sementar itu angket terbuka dianalisis secara kualitatif.

\section{HASIL PENELITIAN}

\section{Hasil Uji Asumsi}

Uji asumsi dilakukan dengan melakukan uji homogenitas dan uji normalitas. Uji homogenitas dimaksudkan untuk mengetahui apakah varian kelompok data sama atau berbeda. Pada output 'Test of Homogeneity of Variances' adalah 0,483 , karena nilai signifikansi lebih besar dari 0,05 (0,483 > 0,05). Kesimpulannya adalah kelompok eksperimen dan kontrol pada awal penelitian (prates) memiliki varian yang sama. Dengan ini maka asumsi homogenitas terpenuhi.

Selanjutnya, dilakukan uji normalitas. Hasil analisis menunjukkan bahwa data kelompok eksperimen dan kelompok kontrol termasuk normal. 


\section{Normal P-P Plot of Regression Standardized Residual}

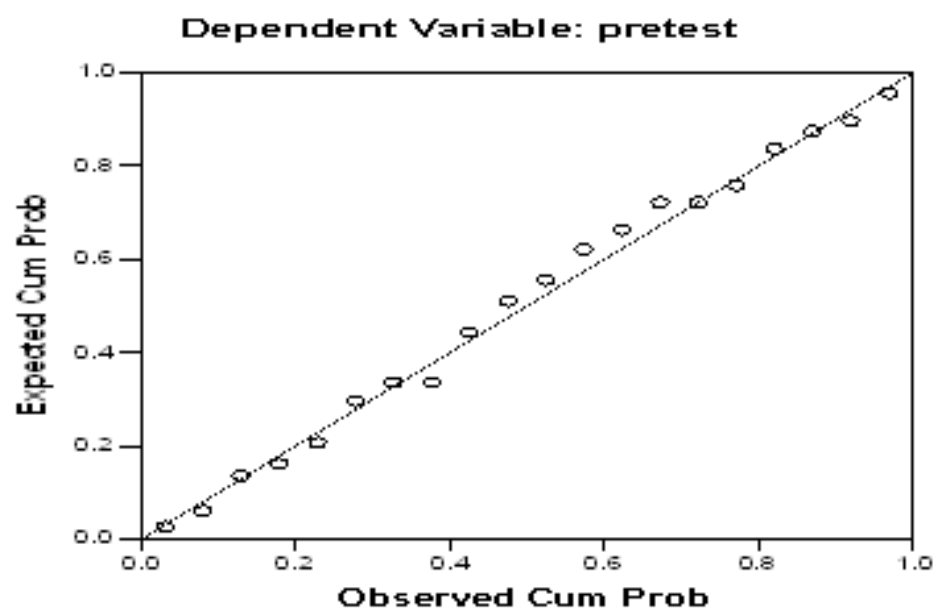

\section{Hasil Uji Hipotesis}

Hasil uji hipotesis yang dilakukan dengan uji beda (t-test) menunjukkan bahwa tidak ada penurunan emosi marah pramurukti pada kelompok eksperimen dibandingkan dengan kelompok kontrol setelah mendapat terapi tawa.

\section{PEMBAHASAN}

\section{Efektivitas Terapi Tawa}

Terapi tawa yang dilakukan tidak memberikan pengaruh secara signifikan terhadap emosi marah. Namun, berdasarkan angket terbuka, diketahui bahwa terapi tawa memberikan dampak bagi peserta, bahkan hampir semua peserta menyatakan bahwa terapi ini sebaiknya dilakukan secara berkesinambungan.

Berdasarkan angket terbuka, hal yang menyebabkan terapi tawa ini tidak berhasil adalah adanya kekhawatiran pada peserta ketika mereka diharapkan dapat mengaplikasikan terapi tawa di posyandu lansia seorang diri. Banyak di antara mereka yang merasa sulit menghapal materi, tidak percaya diri bila harus tampil di depan umum, adanya perasaan takut bila melakukan sesuatu seorang diri, dan adanya rasa takut bila usahanya tidak dihargai.

Rasa takut, tertekan, dan stres dapat meningkatkan zat cortisol dalam darah yang dapat memicu emosi negatif. Hal ini bertentangan dengan fungsi terapi tawa itu sendiri yang dapat menghasilkan endorphin dalam tubuh, sehingga memberikan dampak rasa santai, gembira, dan tenang (Tse, 2010). Para psikoneuroimunolog membuktikan bahwa semua emosi negatif, seperti kecemasan, stres, depresi, atau kemarahan, dapat memperlemah sistem kekebalan tubuh dan dengan demikian mengurangi kemampuan tubuh untuk melawan infeksi. Proses terapi tawa di sini memiliki fungsi 
meredam dan penyeimbangan kekhawatiran peserta. Sedangkan pada rasa marah itu sendiri belum memberikan dampak yang berarti.

Penelitian terapi tawa pada lansia yang mengalami depresi yang dilakukan Shahidi (2010) dan Nugraheni (2006) menunjukkan bahwa terapi tawa memiliki dampak yang sangat signifikan untuk mengurangi depresi. Pada konsep marah yang disampaikan Beck (Mulyono, 2006), proses terjadi depresi harus melalui tahap stres, cemas, marah, muncul rasa bermusuhan, marah pada diri sendiri, hingga akhirnya depresi. Berdasarkan konsep marah yang disampaikan oleh Beck, proses terjadinya emosi marah, memiliki tingkat gangguan emosi yang lebih ringan daripada depresi. Hal inilah yang melatarbelakangi peneliti untuk memberikan terapi tawa lebih singkat daripada terapi yang diberikan pada orang depresi.

Menurut William James dan Carl Lange (Atkinson \& Atkinson, 2005), terjadinya emosi marah memerlukan proses pengaktifan respon visceral dan skeletal dalam tubuh, begitu juga dengan proses terapi tawa. Pada emosi marah, setela ada stimulus yang menjengkelkan dari orang lain, ekspresi berubah, mata melotot, jemari tangan mengepal, bibir cemberut, setelah itu timbul rasa marah. Pada terapi tawa, misalnya orang tersenyum atau tertawa, kemudian tertular ikut tersenyum dan tertawa, maka akan timbul rasa senang, tenang, dan gembira.

Visceral adalah organ-organ tubuh seperti hati, paru-paru, jantung, limpa, dII.
Skeletal adalah rangka tubuh yang menopang tubuh yang terdiri atas otototot dan syaraf (Gulo, 1982). Visceral dan skeletal ini saling bekerja sama satu sama lain dan saling memengaruhi. Proses kerja visceral dan skeletal dipengaruhi oleh faktor struktur, kimiawi, dan emosional.

Terapi tawa memengaruhi otot jantung bekerja. Ketika otot jantung bekerja, maka akan merangsang otot limpa, paruparu, ginjal, kemudian hati. Kecemasan memengaruhi kerja otot limpa. Depresi memengaruhi kerja otot paru-paru. Sedangkan marah memengaruhi keja hati. Proses alur penguatan dari jantung hingga hati, perlu proses dua kali lipat daripada ke paru-paru. Jadi secara struktural, bila menggunakan terapi tawa, proses agar dapat maintenance rasa marah, maka perlu penguatan dan proses terapi dua kali lipat lebih banyak frekuensinya daripada mengatasi depresi (Thie, 2007).

\section{Evaluasi Penelitian}

Hasil dari terapi tawa ini menunjukkan bahwa secara statistik terapi tawa kurang efektif dalam menurunkan rasa marah bila dilakukan dalam waktu yang singkat. Namun, cukup efektif dan terasa dampaknya untuk mengendorkan otototot yang tegang dan rileksasi. Namun demikian dari evaluasi yang dilakukan mulai dari awal hingga akhir penelitian terdapat beberapa keterbatasan. Pertama: Pada awal proses terapi disampaikan bahwa para peserta diharapkan dapat mengaplikasikan terapi tawa di posyandu lansia tanpa bantuan teman. Hal ini 
seharusnya disampaikan sejak awal bahwa mereka dapat tetap saling bekerja sama. Dampaknya adalah munculnya faktor lain yang memengaruhi, misalnya adanya rasa cemas, tidak percaya diri, rasa takut, yang justru menambah kecemasan peserta, dan ini memengaruhi proses pelepasan endorphin dalam tubuh.

Kedua: Pada awal pembuatan modul hingga terapi selesai, peneliti kurang mendapatkan referensi lebih dalam, bahwa proses terapi untuk mengurangi rasa marah secara medis berdasarkan ilmu psikokinesiologi, memerlukan banyak waktu dua kali lipat lebih lama daripada proses penyembuhan depresi. Meskipun dalam ilmu psikologi, depresi merupakan dampak rasa marah yang berlebihan dan tidak diekspresikan.

Ketiga: Pada tahap role play, peneliti lebih terpaku pada agenda yang telah disepakati dari awal dan tidak bernegoisasi kembali untuk tambahan waktu agar pelaksanaan role play yang dirasa kurang, dapat dimaksimalkan.

\section{SIMPULAN DAN SARAN}

\section{Simpulan}

Berdasarkan analisis data dan pembahasan yang dilakukan, dapat disimpulkan bahwa terapi tawa dapat merilekskan tubuh, namun tidak dapat menurunkan emosi marah dalam waktu yang pendek.

Hal ini dapat dilihat dari adanya saran dan hal yang dirasakan setelah proses terapi tawa itu berlangsung. Hampir semua setuju bahwa terapi tawa dapat dilakukan secara rutin dan dapat dilakukan juga di masyarakat. Hal ini menunjukkan bahwa terapi tawa memberikan pengaruh bagi perubahan perilaku pengasuh lansia.

\section{Saran}

Beberapa hal yang perlu disempurnakan agar terapi tawa pada penelitianpenelitian selanjutnya dapat memberikan hasil yang lebih optimal. Pertama: saran bagi pengasuh, yaitu (1) Pengasuh alangkah baiknya dapat menenangkan diri, sehingga dapat berkomunikasi dengan lansia dengan tenang dan santai. (2) Pengasuh alangkah baiknya dapat lebih tenang dan mengatasi rasa khawatir, takut, dan tidak percaya diri ketika memberikan pelayanan pada lansia, dan dapat berbagi dengan penagsuh lain di posyandu lansia. (3) Pengasuh alangkah baiknya dapat saling bekerja sama dengan pengasuh lainnya tanpa rasa marah.

Kedua: saran bagi posyandu lansia, yaitu (1) Perlu adanya keterbukaan dalam wacana baru dalam melayani lansia. (2) Perlu adanya sosialisasi yang terus menurus agar dapat meyakinkan masyarakat tentang peran terapi tawa. (3) Perlu adanya peningkatan sumber daya manusia yang tidak hanya terbatas pada bidang tertentu saja dalam melayani lansia.

Ketiga: saran bagi lembaga terapi, yaitu (1) Lembaga terapi perlu memperhatikan sistematika tahapan terapi tawa dengan lebih seksama. (2) Perlu adanya kerja sama dengan stake holder 
setempat untuk lebih memaksimalkan proses terapi tawa.

Keempat: saran bagi peneliti selanjutnya, yaitu (1) Peneliti selanjutnya perlu memperhatikan tentang faktor-faktor yang sekiranya dapat memengaruhi penelitian.

(2) Peneliti selanjutnya sebaiknya benarbenar melakukan telaah kajian juga terkait penelitian lain dalam bidang kedokteran, bila hal tersebut terkait dengan proses gerak tubuh, otot, pengaktifan respon visceral dan skeletal secara struktural, kimiawi, dan emosional bagi tubuh. (3) Peneliti selanjutnya dapat menelaah lebih lanjut tentang penerapan terapi tawa dalam kehidupan sehari-hari.

\section{DAFTAR PUSTAKA}

Atkinson, R.L. \& Atkinson, R.C. (2005). Pengantar Psikologi I. Jakarta : Penerbit Erlangga.

Beck, R. dan Fernandez, E. (1998). Cognitive-Behavioral Therapy in the Treatment of Anger: A MetaAnalysis. Cognitive Therapy and Research , 22 (1), 63-74.

Billig, M. (2005). Laughter and Ridicule, Towards a Social Crittique of Humour. SAGE Publications.

Cogan, R. (1987). Effects Of Laughter And Relaxation On Discomfort Thresholds. Journal of Behavioral Medicine Volume 10, Number 2, 139-144, DOI: 10.1007/BF00846422
Gulo, D. (1982). Kamus Psikologi. Bandung : Penerbit Tonis.

Hurlock, E.B. (1994). Psikologi Perkembangan. Terjemahan. Jakarta : Penerbit Erlangga.

Kataria, M. (2004). Laugh For No Reason. Jakarta : Gramedia.

Kazhim, M. N. (2009). Manajemen Marah, Seni Mengendalikan Amarah Menjadi Energi Positif. Jakarta : Khalifa.

Middleton, W. (2007). Gunfire, Humour and Psychotherapy. Australasian Psychiatry . 15 (2). 207-218.

Mulyono, R., dan Purwanto, Y. (2006). Psikologi Marah, Perspektif Psikologi Islami. Bandung : PT Refika Aditama.

Nugraheni, A. (2006). Pengaruh Terapi Tertawa Terhadap Depresi Pada Usia Lanjut. Jurnal Intervensi Kedokteran, 1 (2), 189-2005.

Richman, J. (2006). The Role Of Psychotherapy And Humor For Death Anxiety, Death Wishes, And Aging. Omega, vol. 54(1) 41-51.

Schieman, S. (1999). Age and Anger. Journal of Health and Social Behaviour. 40 (September); 273289.

Schultz, D. (1991). Psikologi Pertumbuhan. Yogyakarta : Kanisius.

Shahidi, M. (2010). Laughter Yoga versus group exercise program in elderly depressed women: a randomized 
controlled trial. International of Geriatric Psychiatry. DOI: 10.1002/gps.2545.

Spielberger, A. (1998).

Thie, J. (2007). Touch for Health. Jakarta : Grasindo.

Tse, Mimi M. Y. (2010). Humor Therapy: Relieving Chronic Pain and Enhancing Happiness for Older Adults. SAGE-Hindawi Access to Research. Journal of Aging Research. Volume 2010, Article ID 343574, 9 doi:10.4061/2010/343574.
Wahana Komputer. (2005). Pengembangan Analisis Multivariate Dengan SPSS 12. Jakarta: Penerbit Salemba Infotek

Wooten, P. (1996). Humor an Antidote for Stress. Holistic Nursing Practice. 10 (2), 1996, 49-55. - (2009). Surat Keputusan Tugas Pramurukti di PSTW Yogyakarta.

http://bataviase.co.id/detailberita10423665.html 